\title{
LA VUELTA A CASA DE UN EXTRANJERO: LA POÉTICA DEL INSILIO DE CÉSAR DÁVILA ANDRADE
}

A FOREIGNER'S RETURN HOME: CÉSAR DÁVILA ANDRADE'S SELF-EXILED POETICS

\section{RESUMEN}

A cien años de cumplirse el centenario del nacimiento de César Dávila Andrade es necesario volver a pensar y releer su escritura dada la importancia que tuvo y tiene en las letras ecuatorianas. En consecuencia, es preciso hacer un homenaje reflexivo sobre su legado lírico. El corpus de estudio está conformado por "La casa abandonada", "Canción de nostalgia" y "Carta de la ternura distante", que muestran el deseo de volver a un tiempo y espacio que se han transformado. Este artículo de reflexión se basa en el análisis del contenido, construcción semántica y simbólica, para mostrar qué estrategias utiliza el yo lírico en ese regreso, pues se insilia y exilia como una búsqueda constante de encajar en el mundo que le rodea. Sin embargo, al final se reafirma en una no pertenencia, en un no reconocimiento; en definitiva, en una nostalgia y frustración de eso que fue y no podrá volver a ser.

Palabras clave: César Dávila Andrade, insilio, regreso, memoria

\section{ABSTRACT}

Close to celebrating a hundred years of César Dávila Andrade's birth, it is necessary to think again and reread his writing, given the importance that he had and has in Ecuadorian writing. Consequently, a thoughtful tribute concerning his lyrical poetry is needed due to his legacy. The study corpus comprises "La casa abandonada", "Canción de nostalgia" and "Carta de la ternura distante", which show the desire to return to a time and space transformed. This article is based on the analysis of the content, semantic and symbolic construction, to show what strategies are used by the lyrical "I" in said return, since it self-exiles and exiles, constantly seeking to fit into the world that surrounds it. However, at the end, it reaffirms that it does not belong, it doesn't recognize itself; ultimately, a nostalgia and frustration of that which was and cannot be again.

Keywords: César Dávila Andrade, self-exiled, memory, return, 


\section{INTRODUCCIÓN}

¿Es necesario regresar a casa? ¿Es importante mantener una memoria intacta del lugar de partida? Estos cuestionamientos surgen pues, y a pesar de que, cambiar y migrar son parte de la condición humana, en un momento determinado de esa marcha, también es necesario volver. Esta afirmación se basa en que en ese espacio-tiempo del retorno está el germen, el origen de lo que se es; es decir, la tierra húmeda que fortaleció las raíces. En este sentido, la partida y el regreso serían parte de la condición humana. Sin embargo, también cabe preguntarse: ¿qué pasa si ese viaje transforma al ser y al regresar surge el sentimiento de extrañeza en el propio hogar?

César de Jesús Dávila Andrade (1918-1967) fue un poeta, narrador y ensayista cuencano. Su obra, según Jorge Dávila (1993) se encuentra clasificada en tres etapas: cromático Espacio me has vencido, "Oda al Arquitecto", "Canción a Teresita", "Carta a la madre"-, experimental-telúrico -"Arco de instantes", "Catedral salvaje" y "Boletín y elegía de las mitas", Abandonados en la tierra, 13 relatosy hermético -Cabeza de gallo, En un lugar no identificado, Conexiones de tierra, Poesía del gran todo en polvo; Magia, yoga y poseíaEstas etapas hacen evidente que, para el poeta, la escritura fue la forma de acercarse a un conocimiento, místico en un momento determinado, como respuesta a una vida inquietante $\mathrm{y}$ angustiosa.

En el trascurso de su existencia, como hombre, escritor y ciudadano, se distanció de su círculo, por lo cual se lo consideró como "alguien que no encajó jamás en los modelos usuales del ser y estar burgueses, que no tenía grandes aspiraciones en el terreno de lo convencional" (Dávila Vázquez 1998:37). Por otra parte, el poeta tuvo una existencia "azarosa y atormentada, signada por una conciencia de descentramiento y exilio y por una no menos angustiada búsqueda de afirmación existencial a través de una poesía intensa, extraña y poderosa" (Vintimilla 2012:216).
En consecuencia, su escritura lo llevó por caminos, vericuetos y senderos que lamentablemente desembocaron en un suicidio como último acto de resistencia.

Entre las razones que se señalan para este no encajar del escritor cuencano, por un lado, están las orientaciones políticas. Así, por ejemplo, se inscribió en el Partido Socialista a pesar de que la mayoría de su familia paterna se alineó hacia lo libera, a excepción de su padre quien se mantuvo dentro de una línea conservadora. En otras palabras,

César Dávila era un inconforme, y desde muy joven rechazó las ideas conservadoras de su progenitor, sin que esto quiera decir que simpatizase en exceso con las de sus tíos. Su búsqueda iba por otros derroteros, más amplios, universales y profundos, que en su dialéctico espíritu podía aliar las ideas igualitarias y revolucionarias de socialismo, al que se afiló tempranamente, con las apasionadas persecuciones interiores del espiritualismo de todos los orígenes imaginables. (Dávila Vázquez 1993:11)

Por otro lado, está su propio carácter como un hombre distante, reservado, embargado constantemente por la angustia. Este extrañamiento y extrañeza se manifestaron también en su obra ya que "por su temperamento y por las condiciones singulares de su lírica y de sus cuentos no fue un escritor adherido a una generación o movimiento concretamente determinados" (Dávila Vázquez 1998:50). De todas maneras, tanto lo político como lo personal irían de la mano, y se vería reflejado en su escritura, en su póetica del insilio que se presenta casi como un itinerario para escapar, llegar a un nuevo lugar, y comenzar una nueva fuga.

Sin embargo, es preciso añadir, en primer lugar, que César Dávila Andrade antes de salir y de viajar, ya estaba lejos de casa. Así, la no pertenencia se hacía visible como parte de su identidad -personal, social, política y escritural-, de ahí que las llamadas raíces, en su caso, fueran móviles por esa necesidad 
imperiosa de anclaje. En otros términos, el poeta cuencano estaba siempre más allá de las fronteras y, al mismo tiempo, buscaba que ese nuevo espacio, circunscrito por una línea imaginaria, le diera la posibilidad de una pertenencia vital que se configuraba por medio de la escritura.

En segundo lugar, es necesario resaltar su condición de "extranjero" en Quito, Guayaquil, Mérida y Caracas, sin olvidar, por lo antes señalado, incluso en su natal Cuenca por medio del insilio -entendido como un exilio interior-. César Dávila fue un poeta errante en búsqueda de trabajo y de lectores de su obra, de ahí que la voz poética añorara volver, ya que parece ser que no se encontraba cómodo en ningún sitio, siempre había algo que lo atormentaba. En "Carta de la ternura distante" la voz poética afirma: "Aquí hay pan abundante, pero no tiene aroma / y la ternura esconde como un niño las manos. ¡Qué extraño es todo lo que me rodea! Volveré algún día" (Dávila Andrade 2007:51-52). Partía y tenía la necesidad de regresar, de arraigarse, de mantener una memoria viva; pues el pan, en la distancia, es insípido y todo lo que le rodea, extraño.

\section{METODOLOGÍA}

En este artículo de reflexión se analizan las estrategias para la vuelta a casa en la obra de César Dávila Andrade, basado en la premisa que "toda literatura que se hace es literatura de la memoria" (Colinas 2004:71). Así, el yo poético daviliano regresa mediante el uso de la memoria puesto que él recuerda; y recordar es un proceso de reconstrucción del pasado, al hacerlo se vuelve, por ejemplo, a caminar por la casa, la ciudad, a otros tiempos, a otras sensaciones, a quienes ya no están cerca. Según el diccionario de la Real Academia Española, recordar es "traer a la memoria algo"; al hacerlo se anula el olvido y se actualiza el pasado. Ricardo Forster afir- ma que el binomio memoria y olvido son "estrategias montadas para reescribir la historia" (2003:54); historia que en el poeta cuencano se va reescribiendo a medida que regresa por medio de la evocación.

Algunos de los poemas en los cuales el yo lírico, a través de la memoria, regresa a casa son: "Carta de la ternura distante" y "La casa abandonada" que corresponden al libro Espacio me has vencido en el cual se realiza "un encuentro con la poesía, con esa poesía que está inscrita en la piel del pueblo andino. Ese encuentro también es un caminar, un recorrido por el alma de un pueblo hecho palabra" (Vázquez 2011: 12). Además, se trabaja con el poema "Una canción de nostalgia" que si bien no fue incluido en ningún libro específico, fue recopilado en una versión por la Casa de la Cultura Ecuatoriana (2007).

Los textos referidos fueron analizados en su contenido por medio de la configuración de un campo semántico, que permitirá conocer cuáles son las estrategias utilizadas por la voz lírica para apelar a su memoria. Esta última se ve configurada en la ausencia/presencia de la madre, la niñez y la mujer amada, pues "Lo que brota, en primer lugar, son los símbolos primeros, los arquetipos que se habían fijado en la infancia y en la adolescencia, etapas de la vida que son primordiales para la formación estética del escritor" (Colinas 2004:72).

Por otro lado, esta misma construcción permite la presencia de símbolos como una materialización de ese tiempo-espacio transcurrido. El símbolo propuesto por Solares y Aguirre (2001) "puede regirse por un nexo arbitrario entre el concepto (significado) y su expresión concreta (significante), el símbolo presupone su homo- 
geneidad, factor de la relación necesaria y no convencional entre ambos polos" (11). Es decir, es "imaginación" para construir mediante la voz lírica: el deseo de volver a tres tiempos pasados -madre, niñez y mujer amada- y la desilusión de ese regreso como una paradoja de la poética de César Dávila.

Finalmente, en este estudio es necesario tener en consideración la categoría del insilio que se refiere a la marginación sufrida dentro de las mismas fronteras. Si bien este término fue un neologismo que aparece en la época de las dictaduras latinoamericanas (Dejbord, 1998), permite reflejar ese autoexilio al que se somete Dávila Andrade. En otras palabras, en la poética daviliana la voz lírica no puede ser ni estar dentro de su tierra natal, de ahí que sea necesaria la movilidad como forma de escape, y el consiguiente desencuentro.

\section{RESULTADOS Y DISCUSIÓN}

\section{EI recuerdo como estrategia de regreso a casa}

El deseo de la vuelta a casa es evidente y explícita en la obra de César Dávila Andrade. Para este regreso el yo poético se sirve del recuerdo/memoria como una estrategia. En este sentido, busca a la madre -la niñez como marco temporal- y a la amada como vínculos de regreso, relacionados con el hogar, la juventud y la luz. "Una búsqueda como un caminar interminable" (2011:31), explica José Gregorio Vázquez. En la poética daviliana hay una necesidad de volver, de abrazar, de mirar al ser amado -madre y amante-. No obstante, para que este se materialice, el yo lírico requiere de la aprobación de alguien, quizá la apertura de una situación que le brinde las posibilidades para llevar a cabo su propósito. Esto se hace evidente en una suerte de ruegos expresados en imperativos: "permíteme volver a tu redondo abrazo vespertino, / a tus pequeños labios parpadeantes / entre los que desborda veloz cauce de vino desellado"; "Déjame retornar alguna tarde en el humo de una fotografía / cuando un niño te nazca en los ojos / sobre la virginal labor de lino que bordas con tu 1lanto" (Dávila Andrade 2007:83).

De alguna manera, el yo lírico formula un diálogo con ese tú y le explica el deseo constante de regresar "porque todas las tardes vuelve mi corazón a tus umbrales" (Dávila Andrade 2007:83). "Una canción de nostalgia" es eso, esa necesidad imperiosa de volver, de anular "la muerte de la infancia", de salir de esa oscuridad del olvido. Esta penumbra se configura en la medida en que la nostalgia es ausencia y la ausencia borra/anula al ser. El pedido o ruego de la voz lírica es insistente: "Deja que pueda retornar unos días / con la luz más delgada de mi sangre, / llevándote en las manos; tan delgada y tan tenue que imagines / que llega solo el borde de una llama" (Dávila Andrade 2007:83). De los seis versos que conforman el poema, en los cuatro se encuentran los verbos de retorno: volver y retornar que es casi un agónico cántico, cobijado por una esa ausencia melancólica.

Muchas cosas se olvidan, se pierden -consciente o inconscientemente- en el tiempo, así parecería que es parte de la lógica presencia/ausencia y movilidad-cambio. Esta dialéctica conformaría un ethos entendido como un conjunto de rasgos y modos de comportamiento que darán identidad (RAE, 2017). En este transcurrir del tiempo, el polvo y el moho cubren los recuerdos. La 
memoria es frágil y solo tiene sentido cuando se opone al olvido. Ricardo Forster al respecto se pregunta: " $¿ A$ caso es necesario olvidar para recordar?" (Forster 2003:53). Por supuesto, no obstante, cabe también cuestionarse: ¿cómo se materializa esa memoria, cómo se dejan huellas en el tiempo? La primera estrategia para el poeta es escribir ya que la "palabra es un puente mediante el cual el hombre trata de salvar la distancia que lo separa de la realidad exterior" (Paz 1956:36). Esta realidad intensifica el recuerdo de lo que ya no está, se presenta como la marca y la materialización de la ausencia. Por otro lado, este olvido a veces quiere aniquilar la memoria, es por ello que la voz lírica duda cuando recuerda en "Carta de la ternura distante" se lee: "Tenía creo ya sobre los senos / dorados terroncitos / y algo como azul de la azucena" (Dávila Andrade 2007:51). En este punto, surge otra inquietud ¿para qué retornar más allá de una imperiosa necesidad de recordar? César Dávila, como poeta errante, deja su ciudad natal, abandona las ciudades como un acto de desesperación, y en el deseo de volver se establece la paradoja del regreso y insilio/exilio.

La paradoja se desvanece en la voz de la madre, en "Una canción de nostalgia" se exclama casi como una oración: "O que pueda una noche cerca de tu gemela cara, / escuchar en silencio tus palabras / que cuentan las espigas que aún no muere en mi alma" (Dávila Andrade 2007:83). Sin embargo, el regreso se presenta como un estertor pues se pone en juego el alma de la voz lírica ya que la soledad la enmudece, característica propia del sujeto insiliado. En "Carta de la ternura distante" después de recordar, el poema termina con un gran silencio: "Y por ahora basta. Volveré algún día. / Afuera son las nueve de la noche. Se esconden poco a poco mis palabras..." (Dávila Andrade 2007:52). El silencio surge mientras escucha la voz de la madre, después de escribir y se traduce en una imposibilidad de comunicación, enfatizada por la soledad.

Se afirma que la relación de César Dávila con su madre, Elisa Andrade, fue bastante estrecha. De ahí que este vínculo estuviera caracterizado por la veneración, quizá justamente por las situaciones conflictivas con su padre. No obstante, se considera que este nexo maternal es el punto de anclaje para el regreso, una especie de cordón umbilical o un hilo de Ariadna para no perder el camino. El hogar primigenio es el vientre materno, regresar a él es imposible; sin embargo, ¿cómo se puede retornar a la madre? Se regresa a la cuna uterina por medio del abrazo maternal. Los brazos de la madre lo cobijan y lo abrigan, lo salvan de la ausencia y el silencio. Ella es la única que espera, reza, perdona, entiende al hijo "extraño" que quiere escucharla otra vez:

Déjame sí que vuelva a oír dormido tus pisadas / descendiendo, descalza, a las primeras líneas que hace el alba / en busca de un ligero par de alas / con que subir a los nidos de avena de las torres / o regresar hacia aquel tierno puesto de los tréboles / donde imprimiste el molde inaprensible / de tu cadáver de aire, a mí abrazado. (Dávila Andrade 2007:83)

Ella sube las escaleras, al igual que el encabalgamiento del verso citado, suave y rítmicamente. El hijo escucha su voz, su silencio y sus pasos que ascienden. La madre otorgadora de vida, da también alas al hijo, como Dédalo a Ícaro. Esta analogía provoca un temblor, pues surge la inquietud: ¿el yo poético también descenderá a las aguas del mar? ¿Cuál será su hibris? ¿Qué acto 
trasgresor hará que los dioses lo castiguen? En todo caso, se establece una dicotomía: arriba, las torres; abajo, los tréboles. Además, por un lado, el hijo es una especie de "reproducción" de ese "molde inaprensible del cadáver de aire" de la progenitora. Por otro lado, la reproducción también puede ser entendida como cercanía, casi como un espejo que "está relacionado con la luna, siendo atributo femenino" (Cirlot 2004:201). "Cerca de tu gemela cara" exclama la voz lírica, aquí también se da un autorreconocimiento en la mirada materna.

El recuerdo de la niñez es otra de las estrategias para regresar. A pesar de que esta etapa se ha perdido como "esos barcos de papel cargados de semillas que, a veces, pusimos en el río" (Dávila Andrade 2007:51), el yo lírico vuelve. Esta evocación se manifiesta de manera recurrente en las hora de soledad "porque todo el que va tras sus fantasmas / vuelve al débil cadáver de su infancia / que duerme en el más dulce terrón de los umbrales, / ahí hay un duende preso en el silabario" (Dávila Andrade 2007:83). La infancia está personificada, su vida ha terminado, de ahí que tenga un "débil cadáver"; debilidad que se vincula a la fragilidad de la niñez y cadáver pues al ser el tiempo implacable, la vida se desvanece.

La imagen de la infancia es antitética y oscura, en "La casa abandonada" se lee: "Una niña muerta soñaba un cuento / dicho desde una alta ventana de la niebla. // Hacia atrás viajaba un abecedario, / los días antiguos eran los primeros / por una pequeña compuerta de naipe." (Dávila Andrade 2007:63). Si bien este pasado de abecedario -el tiempo de la escuela- se actualiza al reordenar los días que tal modo que "los antiguos eran los primeros"; este ha desaparecido, es lejano como esa "alta venta- na”. Al recuperar la ventana como símbolo, se encuentra que esta "expresa la idea de penetración, de posibilidad y de lontananza", oportunidades que se ven bloqueadas ya que no puede distinguirse por la niebla que se corresponde con lo "indeterminado" (Cirlot 2004: 462 y 331).

El regreso a la amada es también parte de esta estrategia. Se afirma que el amor para César Dávila fue idealizado. Por su parte, la voz lírica ama un cuerpo joven, adolescente que "Tenía creo ya sobre los senos / dorados terroncitos / y algo como azul de la azucena...". El recuerdo del cuerpo juvenil y casto de la amada está ahí; no obstante, ha cambiado y por eso se pregunta: ¿Tienes aún ese hoyo de nardo en la sonrisa? / ¿y ese nudo de rosas que te rodean los tobillos?". Por otro lado, el sujeto amado se escapa entre sus manos, es frágil y la compara con un jilguero suave, delicado y distante, huidizo y libre: "Por qué tu andar me ha parecido siempre / el temblor de un jilguero entre los mimbres". Además, la amada también es luz, frescura como las flores, inspiración para los músicos, a razón de que "tenían tus pupilas color de té y de arenilla / y bullían en el fondo de tus ojos / esos mínimos puntos luminosos / con que escriben los músicos / las más azules y hondas melodías" (Dávila Andrade 2007:51).

El recuerdo de la mujer amada le hace volver a la ciudad, a lo cotidiano y pregunta: “¿En dónde estás? ¿Qué haces? / ¿Bajas aún al pueblo los domingos? / ¿Y a la feria de rosas de castilla?”. Quizá, el tiempo más feliz sea el domingo de mañana, después de la misa, en la feria. En ese encontrar a la gente y en medio a ella, amada, casta, reluciente, rodeada de rosas. Si un día fuera posible regresar a ese lugar y a ese tiempo, la vida se llenaría de algarabía, de música ya 
que "el maestro de capilla de la aldea / tocará para los dos aquella música / que tiende sobre un río siete puentes de rosas" (Dávila Andrade 2007:51). Dávila Andrade, de esta manera, reconstruye su ciudad natal con el rumor de los ríos atravesándola con aquella música.

\section{La llegada y el desencuentro con el tiempo}

El yo poético, como se afirmó en el apartado anterior, mediante una serie de estrategias, quiere volver; sin embargo, ¿cuándo hacerlo? ¿Existe una hora precisa, un día específico para retornar? En la poética de Dávila, el tiempo para volver son las tardes o las noches de frío, pues la voz lírica cuenta: "(Entré al atardecer, con el sol perdido) [...] Arriba en la tarde flotaba avispas / con lámparas llenas de azufre y de trigo. Arriba en la tarde" (Dávila Andrade 2007:63). El sol puede desaparecer, la niebla cubrir el camino y a pesar de ello, una lámpara alumbrará el sendero.

El tiempo galopa velozmente, y los "profundos caballos de polvo" materializan el peso de los días, como símbolo ctónico-funerario (Cirlot 2004:117). El ambiente es, ahora, árido a diferencia del cuerpo fértil y luminoso de la amada, pues en el patio "lloraba una estatua vacía”. En este contexto, el vacío forma parte de esta desolación, una nada antitética que "entraba con sus muchedumbres / y con sus inmensas campanas ya mudas" (Dávila Andrade 2007:51). Esta se dispersa, es un "hoyo remoto" con movimiento que va consumiendo lo que encuentra a su paso. Irónicamente, el vacío lo llena todo con su vastedad.

El regreso a casa es una evocación cotidiana a los umbrales, al dintel de la puerta que se abre. Al regreso se plantea una nueva interrogante: ¿qué se encuentra en esa casa abandona a la que retorna? La obra de Dávila Andrade "es un camino y son muchos caminos" (Vázquez 2011:32) al igual que la casa. En el recorrido del espacio doméstico se escuchan los gemidos de las estatuas, las cabalgatas de polvo, el ronquido de ese "viento blanquísimo [que] dormía doblado" y el tic-tac del "reloj en ácidos [...] profundos".

La memoria se ha materializado en esos sonidos e incluso -otra vez- en la escritura pues: "(En un muro blanco, hallé esta leyenda: 'El 7 de marzo murió María Eugenia')" (Dávila Andrade 2007:32). Los cuerpos desaparecen, el tiempo pasa, la vida se va. Sin embargo, en ese transcurrir, el ser humano intenta mantener la memoria, por ejemplo, en los epitafios. A pesar de que el muro y la leyenda nos trasladan a los cementerios, esos lugares que crecen y se llenan de nombres y flores marchitas; el nombre permanece, está labrado en la pared para asegurarse de que no haya posibilidad de olvido.

Otro elemento importante es el "viento blanquísimo" que por medio de una prosopopeya "dormía doblado / en un seco lienzo de aves olvidadas" (Dávila Andrade 2007:32). Este viento blanco -"color de muerto", en su sentido negativo (Cirlot 2004:144) evoca el infierno helado de Dante en donde se castiga eternamente a los pecadores para lo cual congela el tiempo y envejece los paisajes. En la poética de César Dávila, el viento es un leitmotiv que arrasa todo por donde pasa y borra las huellas del camino de regreso. Además, aliada de este está la niebla que impide ver a través de la ventana; la cual asimismo hace que el tiempo sea infinito, inabarcable y vasto en donde se pierde el yo poético. 
En consecuencia, el color blanco es trascendental en la poética de Dávila Andrade, entre sus versos encontramos: "blancos cuadernos de ternura,", "frente al camino blanco", "la sagrada blancura de la nieve" y "viento blanquísimo". Por otro lado, el desgaste del tiempo está caracterizado por imágenes y sensaciones; así, en el poema se lee: "Un reloj yacía en ácidos profundos" (Dávila Andrade 2007:32) como "La persistencia de la memoria" de Salvador Dalí en cual unos relojes sumergidos en ácidos cuelgan de unos árboles. El tiempo y la vida se desvanecen, pues las "aves de ceniza" son olvidadas en un "seco lienzo".

\section{CONCLUSIONES}

En la poética daviliana, como se ha demostrado, el regreso es una constante en su escritura. Para ello, la voz lírica utiliza estrategias que le permiten configurar una suerte de cercanía a la madre, la niñez y la amada, a través de símbolos que las representa. En este sentido, se establecen dicotomías, el poeta desciende terriblemente en un alcoholismo, una errancia y, finalmente, un suicidio. Sin embargo, por medio del recuerdo y la memoria, la voz lírica construye la imagen de un ascenso por medio de las torres, la escalera y la lámpara. A su vez este recuerdo se presenta casi con un acto ritual, una primera religiosidad que se hace válida por medio de la repetición de los ritos cuando cruza la puerta, el puente y el río.

Este artículo de reflexión comenzó con la inquietud de si es necesario volver y si es necesario mantener una memoria. La voz lírica daviliana facilita una respuesta afirmativa y al mismo tiempo da lugar a una nueva inquietud: ¿qué sucede con los cambios, la extrañez y la metamorfosis? Es decir, el ser humano, en un momento determinado, desea regresar a casa y mantener una memoria. No obstante, el regreso puede traer desilusiones en la medida en que ese ser estático que que- da en la memoria de los otros puede mutar, "extranjerizarse" -interna y externamente-. En definitiva, todo cambia, la madre envejece, es imposible volver a ser niños, los dorados terroncitos de los senos de la amada son un recuerdo, el pasar del tiempo ha hecho que "las dulces lilas haya muerto en soledad y en frío" (Dávila Andrade 2007: 52). Por otro lado, la casa es ahora un cementerio blanco por el polvo y por la niebla. El epitafio que el yo poético encuentra es la muestra más clara del desaparecer de los cuerpos.

La memoria está ahí, sin embargo, se ha desdibujado, a pesar de que el yo lírico, ha luchado con todas sus fuerzas para mantenerla, para regresar, para reencontrase. Finalmente, regresa, llega, recorre, recuerda, reescribe pero no encaja. Es ajeno, extranjero, e incluso antes ya se había insiliado en su propia casa, quizá hasta en su propia memoria. El regreso termina con un llanto doloroso porque al mutar y al perder las raíces, una parte ha muerto y el regreso pierde sentido. El deseo convertido en plegaria y canción de volver solo ratifica el inevitable paso del tiempo. "Y no era yo el mismo que había vuelto. / Era un extranjero al que a veces lloro y en el que ya he muerto..." (Dávila Andrade 2007:63), concluye la voz lírica. El viento y el caballo configuran esa temporalidad y esa espacialidad que se transforma, y que no permite reconocerse a partir de la imagen del que era cuando se fue. En este sentido, la vuelta a la casa manifiesta una vez más la derrota mediante la vida que se envuelve en la melancolía. Pese a que la memoria lucha pare evitar que el olvido desdibuje los rostros, empolve lo espacios, cubra de tierra los cuerpos inertes; no puede devolver lo que se fue, y jamás volverá a ser. 


\section{REFERENCIAS BIBLIOGRÁFICAS}

Bachelard, G. (1997). El aire y los sueños. México D.F.: Fondo de Cultura Económica.

Cirlot, J. E. (2004). Diccionario de los símbolos. Madrid: Ediciones Siruela S.A.

Colinas, A. (2004). La literatura de la memoria. Centro virtual Cervantes. Recuperado de https://cvc.cervantes.es/literatura/aispi/pdf/17/17 069.pdf

Dávila Andrade, C. (2007). Memoria de vida. Obra poética. Quito: Casa de la Cultura ecuatoriana "Benjamín Carrión".

Dávila Vázquez, J. (1993). Prólogo. César Dávila Andrade. Poesía, narrativa, ensayo. Caracas: Biblioteca Ayacucho.

Dávila Vázquez, J. (1998). César Dávila Andrade, combate poético y suicidio. Cuenca: Universidad de Cuenca.

Dejbord, P. T. (1998). Cristina Peri Rossi: escritora del exilio. Buenos Aires: Galerna.

Forster, R. (2003). Crítica y sospecha. Las clausuras de la cultura moderna. Barcelona: Paidós.

Paz, O. (1956). El arco y la lira. El poema. La revelación poética. Poesía e historia. México D.F.: Fondo de Cultura Económica.

Real Academia Española. Diccionario de la lengua española. Recuperado de: http://www.rae.es/rae.html.

Solares, B. \& Aguirre Lora, Ma. E. (2001). Los lenguajes del símbolo: investigaciones de hermenéutica simbólica. Barcelona: Anthropos.

Vázquez C., J. G. (2011). El vago cofre de los astros perdidos. Antología poética. Caracas: Fundación editorial el perro y la rana/Centro editorial La Castalia.

Vintimilla, Ma. A. (2012). César Dávila: el resplandor del abismo. Revista Pucara 24, 213-248.
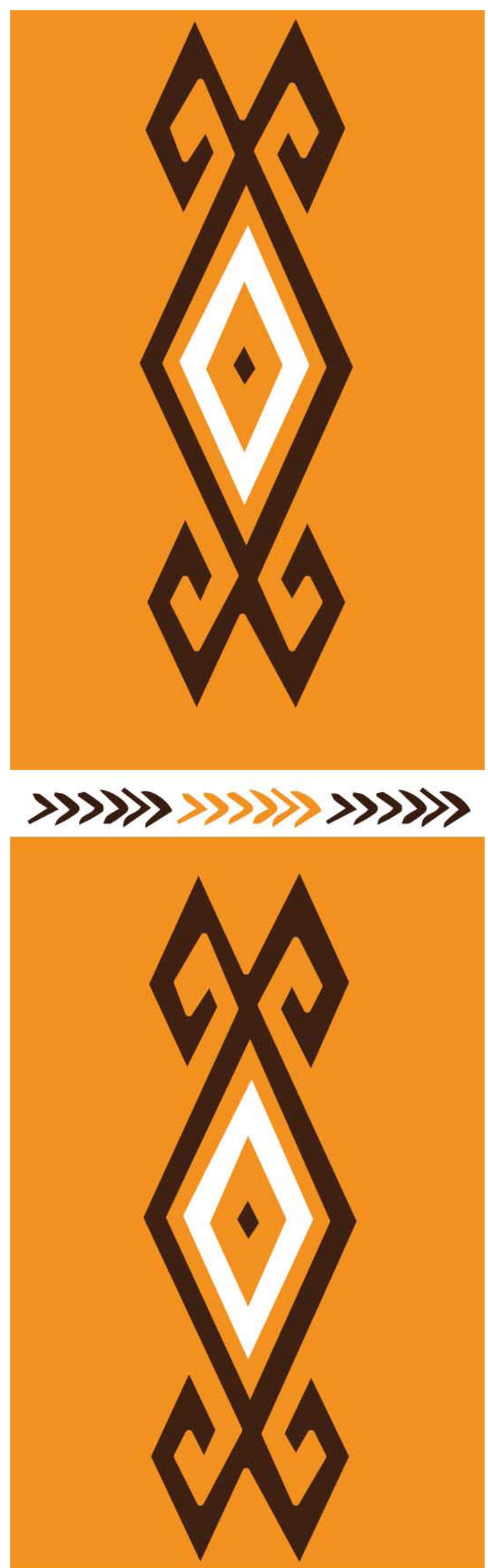